\section{AL-AZHAR}

Assiut Dental Journal
The Official Publication of The

Faculty of Dental medicine.

Al-Azhar Assiut Uniuersity.

AADJ, Vol. 2, No. 1, APRIL (2019) - PP. 85:91

ISSn 2682-2822

\title{
Platelet Rich Fibrin Combined with Nano Crystalline Hydroxyappatite in Treatment of Grade II Mandibular Furcation Defect
}

\author{
Mohamad Fouad Edrees*1, Mona Ahmed Maher1, Khalid Seddik Hassan'
}

Codex : 10/1901

Aadj@azhar.edu.eg

\section{KEYWORDS}

Mandibular fraction, NchHA, osteoblast, PRF

1. Department of Oral Medicine, Periodontology, Oral Diagnosis, and Dental Radiology, Faculty of Dentistry ,Al-Azhar University ,Assiut.

* Corresponding author e-mail: mohamededrees.dent.ast.b@ azhar.edu.eg

\begin{abstract}
Aim: This study aims to evaluate the effect of Platelet Rich Fibrin combined with Nano crystalline Hydroxy appatite bone graft on grade II mandibular furcation involvement. Subjects and methods: Thirty patients having grade II mandibular furcation defects, with vertical probing depth (VPD) $\geq 5 \mathrm{~mm}$ and horizontal clinical attachment level (HCAL) $\geq 3 \mathrm{~mm}$. Following phase I therapy were classified into two groups, group1 received NcHA bone graft and group 2 received $\mathrm{NcHA}+\mathrm{PRF}$. Clinical and radiographic parameters were recorded at baseline, 6 and 12 months postoperatively. Results: Both treatment groups showed a significant probing pocket depth (PPD) reduction, clinical attachment gain, increase bone density 12-months after surgery compared with baseline. However, there was a highly significant PPD reduction and clinical attachment gain when PRF was added to NcHA. Conclusion: The NcHA bone graft in combination with PRF demonstrated clinical advantages beyond that achieved by the NcHA alone.
\end{abstract}

\section{INTRODUCTION}

Furcation involvement is one of the most compelling challenges faced in management of periodontal disease in multi-rooted teeth, resulting from loss of bone adjacent to and within the furcation. ${ }^{(1)}$

In grade II furcation involvement, the bone is destroyed on one or more aspects of furcation but a portion of bone and periodontal ligament remain intact, permitting only partial penetration of the probe into the furcation. The depth of the horizontal component of the pocket will determine whether the furcation involvement is early or advanced. The radiograph may or may not reveal the grade II furcation involvement. ${ }^{(2)}$

Different methods of furcation management therapy include nonsurgical periodontal therapy, open flap debridement, furcation plasty, root resection $\backslash$ Hemisection, regenerative techniques (Guided Tissue Regeneration, bone graft, Enamel Matrix Derivatives) and tunneling. ${ }^{(3)}$ 
In recent years there has been an increased demand for nano materials in treatment of periodontal defects. Different alloplastic bone grafts are being developed with nanoscale particles. The most popular ones to date are Nanohydroxyapatite bone grafts, which has been introduced for augmentation procedures in intrabony defects due to its biocompatibility, bioactivity, osteoconductivity, nontoxicity and non-inflammatory nature ${ }^{(4)}$.

Platelet-rich fibrin (PRF) is a second-generation platelet concentrate, prepared from centrifuged blood. PRF is a fibrin clot rich in platelets without addition of thrombin during preparation. ${ }^{(5)}$

The introduction of PRF clot, which is an attempt to accumulate platelets and cytokines together in a fibrin clot, offers the advantages of being resorpable, biocompatible, acts as a scaffold and also accelerates bone regeneration. ${ }^{(6,7)}$

When HA is combined with PRF, a semi-fluid fibrin meshwork with platetet concentrates and growth factors acting as a barrier membrane, would enhance the regenerative potency. Slow, sustained release of growth factors (such as TGF- $\beta$, PDGF$\mathrm{AB}$, and vascular endothelial growth factor) and glycoproteins (such as thrombospondin-1) during $\geq 7$ days and its well organized tertramolecular fibrin meshwork adds to its application as covering membrane, protecting the intrabony defect site from epithelial invasion. ${ }^{(8)}$

The present study was designed to evaluate the clinical and radiographic effect of Nano crystalline hydroxy appatite bone graft combined with Platelet Rich Fibrin in treatment of grade II furcation involvement.

\section{SUBJECTS AND METHODS}

The current study included thirty systemically healthy subjects ( 26 males and 4 females, mean age of $41.5 \pm 3,4$ years) undergoing periodontal therapy at the Out Patients Clinic, Department of Oral Medicine and Periodontology, Faculty of Dentistry, Al-Azhar University (Assiut branch). All eligible patients were thoroughly informed of the nature, potential risks and benefits of their participation in the study and signed their informed consent documents.

\section{Inclusion criteria:}

The presence of degree II furcation defects (Ramfjord \& Ash 1979) ${ }^{(9)}$ in vital, asymptomatic mandibular first molars with a radiolucency in the furcation area on an intra-oral periapical radiograph, vertical probing depth (VPD) $\geq 5 \mathrm{~mm}$ and horizontal clinical attachment level (HCAL) $\geq 3 \mathrm{~mm}$ following phase I therapy (scaling and root planning). Patients were divided randomely by flik of coin toss into two groups; (G1) treated with Nanocrystalline hydroxyapatite and (G2) treated with Nanocrystalline hydroxyapatite combined with platelet rich fibrin.

\section{Periodontal and radiographic evaluation:}

1. Periodontal evaluation and clinical parameter were recorded before surgical procedures included vertical probing depth (VPD), ${ }^{(10)}$ relative clinical attachment level (RCAL) ${ }^{(11)}$, plaque $^{(12)}$ and gingival index ${ }^{(13)}$.

2. Radiographic evaluation was done at; baseline, 6 and 12 months post surgically. A standardized periapical radiographs were taken using long cone parallel technique, customized bite, metal rod and parallel dental film positioning system.

\section{PRF preparation:}

A blood sample of the patient was drawn in $10 \mathrm{~mL}$ test tubes without an anticoagulant and centrifuged immediately. Blood was centrifuged for $10 \mathrm{~min}$ at $3000 \mathrm{rpm}^{(14)}$. The resultant product consisted of the following three layers; the upper layer of acellular PPP (platelet-poor plasma), PRF clot in the middle and red blood cells at the bottom. PRF was easily separated from red corpuscules base using a sterile tweezers and scissors and then transferred mixed by NcHA crystals. 


\section{Surgical procedures:}

1. Intra-oral antisepsis was performed with $0.12 \%$ chlorhexidine digluconate rinse

2. Surgical site was anaesthetized by block anesthesia.

3. A full thickness sulcular incision was made using scalpel and surgical blade No.15c.

4. The full thickness mucoperiosteal flap was elevated using mucoperiosteal elevator. Meticulous defect debridement and root planning were carried out using Gracy curettes (Hu Friedy, IL, Chicago) and ultrasonic instruments.

In Group 1: the surgical furcation defect was filled by Nanocrystalline hydroxyapatite (NcHA) (Nano-bone ${ }^{\circledR}$ (ARTOSS GmbH friedrich-Barnewitz-straBe3118119 Rostock/ Germany), while in group2 the defect was filled by mixture of PRF and NcHA (Fig 1,2,3).

5. The flaps were sutured coronally using 3-0 or 4-0 absorbable vecryl surgical suture with interrupted sutures.

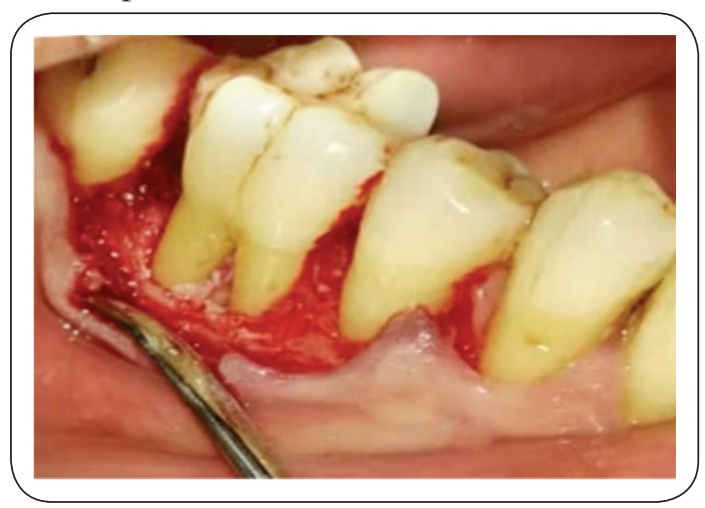

Fig. (1) Show furcation grade defect

\section{Post-surgical instructions and medications:}

1. Patients were placed on systemic antibiotic, analgesic for one week and mouth wash for 4 weeks.

2. Patients were advised with repeated application of an ice pack over the area of the face related to the surgery for one day to avoid post-surgical edema. In the 1st week post surgically patients were asked to avoid sticky, spicy, hard and crispy food. The patients were instructed to discontinue tooth brushing around the surgical sites during the initial 10 days after surgery.

\section{Post-surgical evaluations:}

1. Clinical soft tissue measurement: The sitespecific plaque index (PI), gingival index(GI), vertical probing depth (VPD), relative clinical attachment level (RCAL) were recorded at 6 and 12 months post surgically.

2. Standardized periapical radiographs were repeated at 6 and 12 months postsurgical.

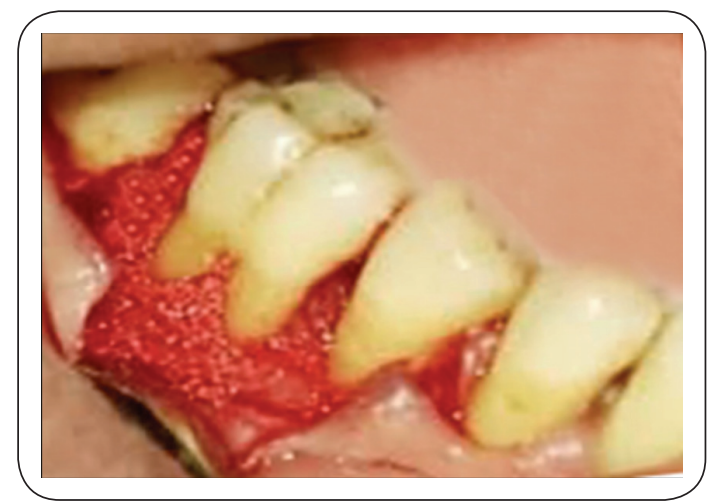

Fig. (2) Show furcation defect filled with mixture of NcHA+PRF

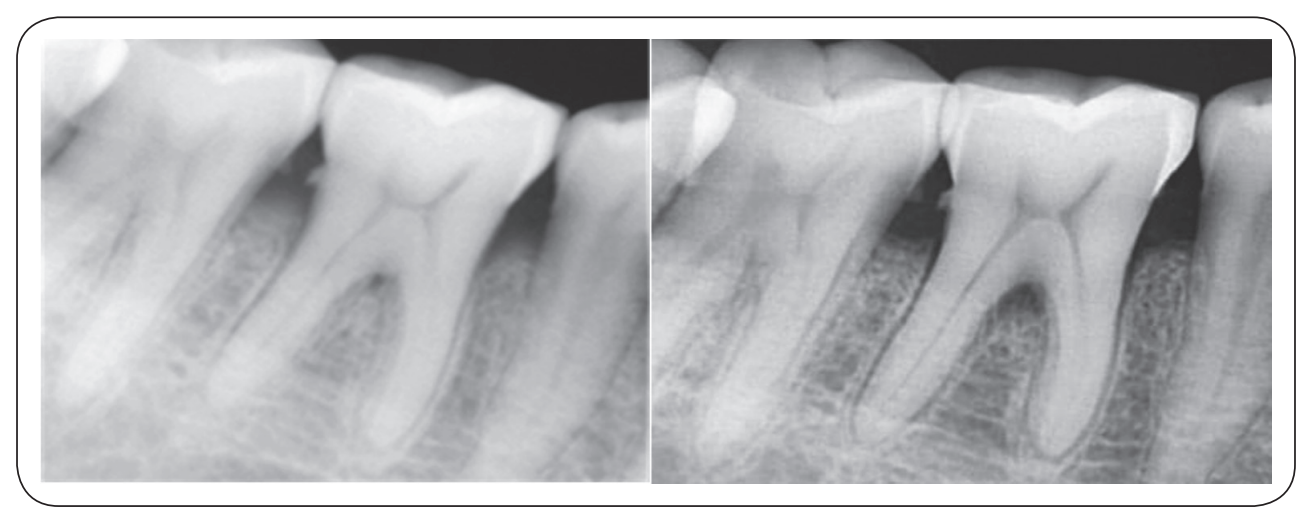

Fig. (3) Show furcation defect at base line and 12 month postsurgical after treatment with NcHA +PRF 


\section{Statistical analysis:}

The data were collected, tabulated and statistically analyzed by IBM ${ }^{\circledR}$ SPSS ${ }^{\circledR}$ Statistics Version 20 for Windows using ANOVA test. 1-Data were explored for normality using KolmogorovSmirnov and Shapiro-Wilk tests, Plaque index and Gingival index data showed non-parametric (not-normal) distribution, while Pocket depth, RCAL and Bone density data showed parametric (normal) distribution. 2-Pearson test was used to test the correlation between different variables. The significance level was set at $\mathrm{P} \leq 0.05$.

\section{RESULTS}

Thirty patients with chronic periodontitis and class II furcation defects in vital, asymptomatic mandibular first molars with a radiolucency in the furcation area on an intra-oral periapical radiograph, vertical probing depth (VPD) $\geq 5 \mathrm{~mm}$ and horizontal clinical attachment level (HCAL) $\geq 3 \mathrm{~mm}$ following phase I therapy were selected to participate in the present study.

During the periods of the study there was no abnormal reaction and complications were observed after periodontal therapy.

The changes in the mean values of clinical and radiographic parameters during the observation periods of the present study were illustrated in tables (1)

TABLE (1) Demonstrate the statistical comparisons of clinical parameters at time interals; baseline, 6 month and 12 month in group 1 and group2

\begin{tabular}{|c|c|c|c|}
\hline Parameter & Interval & G1 & G2 \\
\hline \multirow{3}{*}{ PI } & base line & $0.81 \pm 0.06$ & $0.75 \pm 0.07$ \\
\cline { 2 - 4 } & 6month & $0.72 \pm 0.08$ & $0.64 \pm 0.10$ \\
\cline { 2 - 4 } & 12 month & $0.64 \pm 0.06$ & $0.62 \pm 0.08$ \\
\cline { 2 - 4 } & p value & $<0.001 *$ & $0.002 *$ \\
\hline
\end{tabular}

\begin{tabular}{|c|c|c|c|}
\hline Parameter & Interval & G1 & $\mathrm{G} 2$ \\
\hline \multirow{4}{*}{ GI } & base line & $0.75 \pm 0.09$ & $0.70 \pm 0.14$ \\
\hline & 6month & $0.70 \pm 0.08$ & $0.63 \pm 0.13$ \\
\hline & 12 month & $0.64 \pm 0.08$ & $0.60 \pm 0.12$ \\
\hline & $\mathrm{p}$ value & $<0.001 *$ & $<0.001 *$ \\
\hline \multirow{4}{*}{ PD } & base line & $5.87 \pm 0.31$ & $5.82 \pm 0.75$ \\
\hline & 6month & $4.89 \pm 0.32$ & $4.22 \pm 0.20$ \\
\hline & 12 month & $3.82 \pm 0.23$ & $0.21 \pm 3.23$ \\
\hline & $\mathrm{p}$ value & $<0.001 *$ & $<0.001 *$ \\
\hline \multirow{4}{*}{ RCAL } & base line & $7.62 \pm 0.38$ & $7.90 \pm 0.42$ \\
\hline & 6month & $6.19 \pm 0.32$ & $5.39 \pm 0.51$ \\
\hline & 12 month & $4.83 \pm 0.43$ & $0.15 \pm 3.98$ \\
\hline & $\mathrm{p}$ value & $<0.001 *$ & $<0.001 *$ \\
\hline \multirow{4}{*}{$\mathrm{BD}$} & base line & $101.95 \pm 14.04$ & $100.49 \pm 5.31$ \\
\hline & 6month & $120.70 \pm 10.66$ & $127.00 \pm 6.20$ \\
\hline & 12 month & $136.42 \pm 9.92$ & $4.50 \pm 148.05$ \\
\hline & $\mathrm{p}$ value & $<0.001 *$ & $<0.001 *$ \\
\hline
\end{tabular}

$G 1=N c H A G 2=N c H A+P R F P I=$ plaque Index $G I=$ Gingival Index $P D=$ pocket debth $R C A L=$ Relative Clinical Attachment Level BD=Bone Denesity significant*; $(p<0.05)$ ns; non-significant $(p>0.05)$

\section{DISCUSSION}

Chronic periodontitis in individual patients with severe attachment loss can be treated successfully with a variety of methods that are often combined. regeneration is the main objective of therapy in these patients with severe bone loss. A variety of bone grafts have been used for many years to treat chronic periodontitis with severe attachment loss. The objectives of these matrials are probing depth reduction,clinical attachment gain and regeneration of new bone, cementum and periodontal ligament ${ }^{(15)}$.

Bone substitutes in the form of Nano hydroxyapatite can be used successfully to fill osseous defect as it has advantages like close contact with surrounding tissues, quick resorption characteristics and large number of molecules on the surface ${ }^{(16)}$. 
Platelet-rich fibrin (PRF) is in the form of platelet gel and can be used in conjunction with bone grafts, which offers several advantages including promoting wound healing, bone growth and maturation, graft stabilization, wound sealing, and hemostasis and improving the handling properties of graft materials ${ }^{(17)}$.

The current study assesses clinical and radiographic parameters to evaluate the effect of $\mathrm{NcHA}$ combined with PRF in the treatment of mandibular grade II furcation defects.

The present study showed a statistical significant difference in both groups at different time intervals in the form of significant reduction in pocket depth, gain in clinical attachment and level of bone fill at sites treated with NcHA (G1) with p-value $<\mathbf{0 . 0 0 1}$, This in accordance with study by Prathap et al ${ }^{(18)}$ used n-HA in the treatment of bilateral grade II furcation involvement in the mandibular first molars and concluded that application of $\mathrm{n}-\mathrm{HA}$, resulted in a significant horizontal and vertical probing depth reduction and clinical attachment level gain.

There were statistical significant difference in pocket depth, clinical attachment level and bone density in patients treated with $\mathrm{NcHA}$ and $\mathrm{PRF}(\mathrm{G} 2)$ where $\mathrm{p}$-value $<\mathbf{0 . 0 0 1}$ this in accordance with the study by Pradeep AR 2011(19) who reported that, greater reduction of pocket depth, greater gain in RVAL and RHAL and significantly greater percentage of mean bone fill when using HA with PRF in class II furcation involvement.

In the present study the improvement in mean values of probing depth, clinical attachment level and bone density in patients treated by $\mathrm{NcHA}+\mathrm{PRF}$ was greater than those in patients treated with $\mathrm{NcHA}$ bone graft alone this was in accordance with study by Atiaa AM 2015, ${ }^{(20)}$ which concluded that the improvement was greater in patient with class II Furcation treated with NcHA +PRF than patients treated with $\mathrm{NcHA}$ bone graft alone this may be due to the senergistic effect of both $\mathrm{NcHA}$ and PRF.
Results of the present study were in accordance with a study by Nagasri $M$ et al., 2016 ${ }^{(21)}$ who concluded that there were improvement on probing depth, Clinical attachment level and radiograghic bone fill when using NcHA bone graft + Platelet rich fibrin in intrabony defect, and a study by Enas ahmed et $\mathrm{al}^{(4)}$ who concluded that Adjunctive use of PRF membrane in combination with $\mathrm{NcHA}$ bone graft in treatment of intrabony defect resulted in clinically, radiographically statistically significant compared with NcHA bone graft alone, in terms of PPD reduction, CAL gain and increase $\mathrm{BD}$. In another study by Rahman Siddiqui et al $2016^{(22)}$ vertical and horizontal height of furcation was better when using PRF in treatment of class II furcation involvement.

Finally, to our knowledge there are a few studies reporting the use of $\mathrm{NcHA}$ combined with PRF in the treatment of furcation defects.There for a direct comparison with other studies is so deficult.

\section{CONCLUSIONS}

1. Both NcHA and NcHA/PRF significantly improved the clinical parameters and bone density.

2. The adjunctive use PRF combined with $\mathrm{NcHA}$ bone graft resulted in clinically and radiographically statistically significant compared with $\mathrm{NcHA}$ bone graft alone.

3. Nanocrystalline hydroxy appatite can be used as promising bone graft in the treatment of furcation defects

\section{REFERENCES}

1. Parihar AS, Kotach V, Furcation involvement \& Its Treatment; A Review. J Adv Med Dent Scie Res 2015; (1):81-87.

2. Ammons WF, Harrington GW: Furcation, the Problem and Its Management. In Newman, Takei, Carranza, editors: Carranza's Clinical Periodontology, 9th Edition. Philadelphia: W.B. Saunders Co. 2002; 826-7.

3. Lindhe, J.Land N Korring T.Clinical periodontology and implant dentistry 5th ED. Copenhagen; Munksgaard 2008; 823-47 
4. Enas Ahmed Elgendy Tamer Elamer Abo Shady. Clinical and radiographic evaluation of nanocrystalline hydroxyapatite with or without platelet rich fibrin membrane in the treatment of periodontal intrabony defects. J Ind soci of periodontol - 2015;19(1):61.

5. Dohan DM, Choukroun J, Diss A, et al. Platelet-rich fibrin (PRF): a second-generation platelet concentrate. Part II: Platelet related biologic features. Oral Surg Oral Med Oral Pathol Oral Radiol Endod 2006; 101:E45-50.

6. Gupta SJ, Jhingran R, Gupta V, Bains VK, Madan R, Rizvi I. Efficacy of platelet-rich fibrin vs. enamel matrix derivative in the treatment of periodontal intrabony defects: A clinical and cone beam computed tomography study. J Int Acad Periodontol 2014; 16:86-96.

7. Mathur A, Bains VK, Gupta V, Jhingran R, Singh GP. Evaluation of intrabony defects treated with platelet-rich fibrin or autogenous bone graft: A comparative analysis. Eur J Dent 2015; 9:100-8.

8. A R Pradeep, Shruti Karvekar, Kanika Nagpal, Kaushik Patnaik,Arjun Raju, Priyanka Singh. Rosuvastatin 1.2mg in Situ Gel Combined ith 1:1 Mixture of Autologous Platelet-Rich Fibrin and Porus- Hydroxyappatite Bone Graft in Surgical Treatment of Mandibular Degree II Furcation Defects: A Randomized Clinical Control Trial. J of Periodontol 2016;87(1):5-13.

9. Ramfjord SP \& Ash MM: Periodontology and periodontics. Philadelphia:WB Saunders 1979; 465-483.

10. Polson, Caten J, Yeaple R, and Zander H. Histologic determination of probe tip penetration into gingival sulcus of human using an electrosonic pressure sensitive probe. $\mathrm{J}$ Clin peridontol. 1980;7:479-488.

11. Ramfjord S. The periodontal disease index. J periodontol. 1967; 38:602-10

12. Silness J \& Lo“e H: Periodontal disease in pregnancy. II. Correlation between oral hygiene and periodontal condition. Acta Odontolgia Scandinavia 1964;22: 121-135.

13. Loe $\mathrm{H}$, Silness. The gingival index, and the retention index system. J periodontol.1967; 38:610-6.
14. Choukroun J, Adda F, Schoeffer C, Vervelle A. PRF: an opportunity in perio-implantology. Implantodontie 2000;42:55-62 in French.

15. Thomas G. Wilson, Kenneth S.Kornman, Fundamentals of periodontics. Second edition quitescense publishing co.2003. P. 447.

16. Mansi Bansal, Mayur Kaushik. Comparison of nanocrystalline hydroxyapatite and synthetic resorbable hydroxyapatite graft in the treatment of intrabony defects: A clinical and radiographic study. J Ind soci of periodontol 2014;18(2):213

17. Sclafani AP. Applications of platelet rich fibrin matrix in facial plastic surgery. Facial Plast Surg 2009;25(4):270-6.

18. Sruthy Prathap, Shashikanth Hegde, Rajesh Kashyap, M. S. Prathap, M. S. Arunkumar Clinical evaluation of porous hydroxyapatite bone graft (Periobone G) with and without collagen membrane (Periocol) in the treatment of bilateral grade II furcation defects in mandibular first permanent molars 2013;17, (2): 228-234

19. Pradeep AR, Sharma A. Autologous platelet rich fibrin in the treatment of mandibular Degree II furcation defects: a randomized clinical trial. J Periodontol. 2011; 82:13961403.

20. Attia AM Platelet Rich Fibrin and Nano Crystallin Hydroxy Appatite in treatment of periodontal class II furcation defect: Clinical and Radiographic study 2015; 61, 5049:5063.

21. Nagasri M., Bindu Madhuri, Musalaih S.V.V.S., Aravind Kumar. P And Indeevar.P, Clinical and radiographic evaluation of nanocrystalline hydroxyapatite with Advanced Platelet Rich Fibrin (APRF)and Platelet Rich Fibrin (PRF) in the treatment of Bilateral intra bony defect. 2016;7(4):10699-10706.

22. Siddiqui ZR, Jhingran R, Bains VK, Srivastava R, Madan $\mathrm{R}$ Comparative evaluation of platelet-rich fibrin versus beta-tri-calcium phosphate in the treatment of Grade II mandibular furcation defects using cone-beam computed tomography. Europian Journal of Dentistry.2016;10(4): 496-506. 


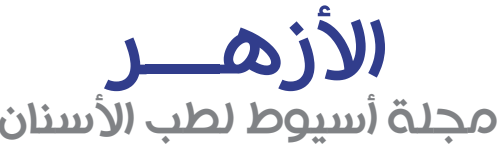

النشر الرسمي لكلية طب الأسنان

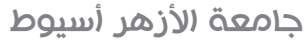

AADJ, Vol. 2, No. 1, April (2019) - PP. 91

الملخص العربي

الردف من الدراسة:

تهدف هده الدراسـة الي تقييم تأثير الصفائح الدموية الغنية بالليفين ممزوجة ببدائل عظميه من حبيبات الهيدروكسي أباتيت متناهية الصغر

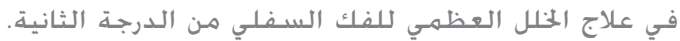

الموضوعات والأساليب:

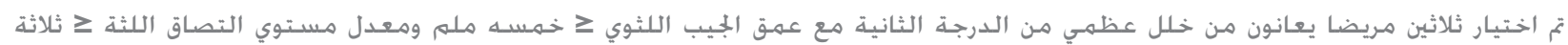

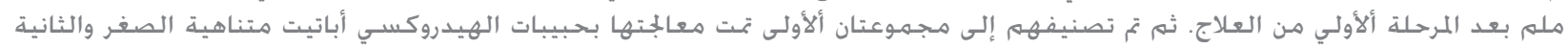

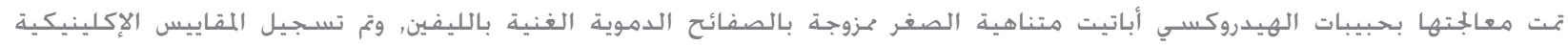

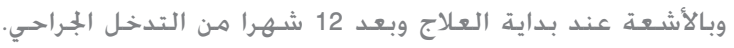

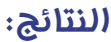

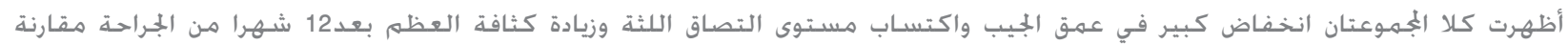

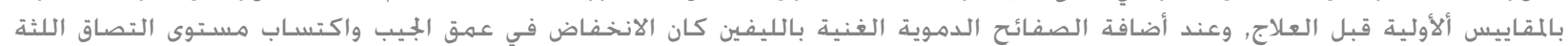

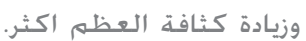

الاستنتاج:

أظهرت الصفائح الدموية الغنية بالليفين مـزوجة مع حبيبات الهيدروكسي أباتيت متناهية الصغر نتائج أفضل بكثير من نتائج حبيبات الهيروكسي أباتيت متناهية الصغر وحدها. 